\title{
Analisis Faktor - Faktor Yang Mempengaruhi Pendapatan Nelayan Juragan Tangkapan Ikan Teri (Studi Kasus : Kelurahan Belawan Bahari Kecamatan Medan Belawan Kota Medan)
}

\author{
Stefanus Lugu, *Mitra Musika Lubis, SP. M.Si, Rahma Sari Siregar, SP. M.Si. \\ Prodi Agribisnis Fakultas Pertanian Universitas Medan Area
}

Diterima: Agustus 2019 Disetujui: Oktober 2019 Dipublish: Oktober 2019

*Coresponding Email: mitra.lubis@yahoo.co.id

\begin{abstract}
Abstrak
Penelitian ini bertujuan untuk mengetahui tingkat pendapatan nelayan juragan tangkapan ikan teri dan menganalisis faktor - faktor yang mempengaruhinya. Penelitian dilakukan dengan metode purposive sampling. Hasil penelitian menunjukkan bahwa : Variabel biaya produksi berpengaruh negatif dan tidak signifikan terhadap pendapatan nelayan juragan, hal ini disebabkan karena semakin besar biaya produksi yang dikeluarkan, maka pendapatan bersih yang diperoleh semakin berkurang. Variabel jumlah tenaga kerja berpengaruh positif dan signifikan terhadap pendapatan nelayan juragan, hal ini disebabkan karena apabila semakin besar jumlah tenaga kerja, maka kecepatan dalam memperoleh hasil tangkapan (produksi) lebih efektif. Variabel jarak tempuh melaut berpengaruh positif dan signifikan terhadap pendapatan nelayan juragan, hal ini disebabkan karena apabila semakin jauh jarak tempuh melaut, maka semakin bertambah pula jumlah pendapatan nelayan juragan. Variabel pengalaman usaha berpengaruh positif dan signifikan terhadap pendapatan nelayan juragan, hal ini disebabkan karena apabila semakin lama atau semakin banyak pengalaman usaha, maka dalam memanajemen modal usaha dalam memperoleh hasil lebih baik dan teliti, sehingga pendapatan lebih maksimal. Variabel biaya produksi, jumlah tenaga kerja, jarak tempuh melaut dan pengalaman usaha secara bersama - sama berpengaruh terhadap variabel pendapatan.
\end{abstract}

Kata Kunci : Nelayan Juragan, Biaya Produksi dan Pendapatan.

\begin{abstract}
This study aims to determine the income level of fishermen anchovy catchers and analyze the factors that influence it. The research was conducted by purposive sampling method. The result showed that: Production Cost Variables had a negative and insignificant effect on the income of skipper fishermen, this was due to diminshing returns. Variable Amount of Labor has a positive and significant effect on the income of skipper fishermen, this is because if the greater the amount of work, the speed in obtaining the catch (production) is more effective. Variety of Sea Trips has a positieve and significant effect on the income of fishermen, this is because if the distance goes to sea, then the amount of income of fishermen's fishers increases. Variable Experience of skipper fishermen income, this is because if the longer or more business experience, then in managing business capital in obtaining results better and more accurate, so that income is maximized. Variable Production Costs, Number of Workers, Mileage, and Business Experience together influence the income variable.

Keyword : Skipper Fishermen, Production Costs and Revenues.

How to Cite: Lugu, S. Lubis, M.M., \& Siregar, R.S. 2019. Analisis Faktor - Faktor Yang Mempengaruhi Pendapatan Nelayan Juragan Tangkapan Ikan Teri (Studi Kasus : Kelurahan Belawan Bahari Kecamatan Medan Belawan Kota Medan) Jurnal Agriuma. 1(2): 103-114.
\end{abstract}


Stefanus Lugu, *Mitra Musika Lubis, SP. M.Si, Rahma Sari Siregar, SP. M.Si, Analisis Faktor - Faktor Yang Mempengaruhi Pendapatan Nelayan Juragan Tangkapan Ikan Teri (103-114)

\section{PENDAHULUAN}

Nelayan adalah orang yang hidup dari mata pencaharian hasil laut. Di Indonesia para nelayan biasanya bermukim didaerah pinggir pantai atau pesisir laut. Komunitas nelayan adalah kelompok orang yang bermata pencaharian hasil laut dan tinggal didesa - desa pantai atau pesisir (Sastrawidjaya, 2002). Secara umum nelayan adalah sebutan untuk orang - orang yang bekerja/pekerjaan utamanya menangkap ikan dilaut, tinggal/bermukim didaerah pesisir dan pinggiran pantai dan menggantungkan kehidupannya dari hasil laut.

Pekerjaan nelayan merupakan pekerjaan turun temurun dan umumnya tidak banyak mengalami perubahan yang berarti. Dalam masyarakat nelayan ditemukan adanya kelas pemilik dan kelas pekerja. Kelas pemilik yang dapat dinyatakan sebagai juragan, kesejahteraannya relatif lebih baik karena menguasai faktor produksi seperti kapal, mesin alat tangkap maupun faktor pendukungnya seperti es, garam dan lainnya. Kelas pekerja atau penerima upah dari pemilik merupakan mayoritas, dan kalaupun mereka berusaha memiliki sendiri alat produksi, umumnya masih sangat konvesional, sehingga produktivitasnya kurang berkembang, kelompok inilah yang terus berhadapan dan digeluti oleh kemiskinan (Ninda, 2009 dalam Kamaluddin, 2014).

Subsektor perikanan memberikan kontribusi terbesar ketiga yaitu sebesar 9,91\%. Pada sektor dari tahun 2010 s/d 2014 mengalami peningkatan yang signifikan, dimana pada tahun 2010 yaitu mencapai 8,58\% meningkat hingga pada tahun 2014 yaitu 9,91\%. Kontribusi sektor pertanian dalam pendapatan regional Sumatera Utara secara lengkap dapat dilihat pada tabel 1.

Tabel 1. Peranan Subsektor Pertanian terhadap Sektor Pertanian Sumatera Utara Atas Dasar Harga Berlaku tahun 2010-2014 (persen).

\begin{tabular}{llllll}
\hline Subsektor & \multicolumn{1}{c}{ Tahun } & & & & \\
\cline { 2 - 5 } & $\mathbf{2 0 1 0}$ & $\mathbf{2 0 1 1}$ & $\mathbf{2 0 1 2}$ & $\mathbf{2 0 1 3}$ & $\mathbf{2 0 1 4}$ \\
\hline Tanaman Bahan Makanan & 28,26 & 27,7 & 27,32 & 26,71 & 26,09 \\
Tanaman Perkebunan & 50,65 & 51,38 & 51,42 & 51,86 & 51,12 \\
Peternakan dan hasil-hasilnya & 8,4 & 8,25 & 8,32 & 8,25 & 8,74 \\
Kehutanan & 4,11 & 3,99 & 3,96 & 3,96 & 4,14 \\
Perikanan & $\mathbf{8 , 5 8}$ & $\mathbf{8 , 6 8}$ & $\mathbf{8 , 9 3}$ & $\mathbf{9 , 2 2}$ & $\mathbf{9 , 9 1}$ \\
Peternakan & 100,00 & 100,00 & 100,00 & 100,00 & 100,00 \\
\hline
\end{tabular}

Sumber : BPS Provinsi Sumatera Utara, 2015.

Menurut Sastria (2002), nelayan dikelompokkan berdasarkan status penguasaan kapital, yaitu terdiri dari nelayan pemilik dan nelayan buruh. Nelayan pemilik atau juragan adalah orang yang memiliki sarana penangkapan seperti kapal/perahu, jaring dan alat 
tangkap lainnya sedangkan nelayan buruh adalah orang yag menjual jasa tenaga kerja sebagai buruh dalam kegiatan penangkapan ikan dilaut, atau sering disebut Anak Buah Kapal (ABK).

Bahkan menurut Retno dan Santiasih (1993:137), jika dibandingkan dengan kelompok masyarakat lain disektor pertanian, nelayan (terutama nelayan buruh dan nelayan tradisional) dapat digolongkan sebagai lapisan sosial yang paling miskin, walaupun tidak dapat dikatakan semua nelayan itumiskin.

Hal ini yang melatarbelakangi akan dilakukan penelitian untuk mengetahui bagaimana tingkat pendapatan nelayan dan faktor-faktor apa saja yang mempengaruhi pendapatan nelayan juragan tangkapan ikan teri di Kelurahan Belawan Bahari Kecamatan MedanBelawan.

Berdasarkan latar belakang diatas rumusan masalah yang dikaji dalam penelitian ini adalah bagaimana tingkat pendapatan nelayan juragan dan faktor - faktor apa saja yang mempengaruhi pendapatan nelayan juragan dengan tujuan untuk mengetahui tingkat pendapatan nelayan juragan dan mengetahui faktor - faktor apa saja yang mempengaruhi pendapatan nelayan juragan.

\section{METODE PENELITIAN}

Lokasi penelitian ini dilakukan di Kelurahan Belawan BahariKecamatanMedan Belawan Kota Medan. Lokasi penelitian ditentukan secara purposive atau dipilih secara sengaja dengan pertimbangan bahwa didaerah tersebut merupakan daerah pesisir pantai dimana Kelurahan Belawan Bahari memiliki jumlah nelayan terbanyak ketiga dari enam kelurahan di Kecamatan Medan Belawan. Penelitian ini dilaksanakan pada bulan oktober 2017. Sampel dalam penelitian ini adalah nelayan juragan di Kelurahan Belawan Bahari Kecamatan Medan Belawan. Teknik pengambilan sampel dalam penelitian ini digunakan teknik sampling accidental. Dengan sampel yang ambil sebanyak 30 sampel nelayan juragan. Metode pengumpulan data dilakukan dengan metode observasi (teknik pengamatan langsung) dan metode survei. Dalam penelitian ini metode tersebut dilakukan pada nelayan di Kelurahan Belawan Bahari Kecamatan Medan Belawan Kota Medan. Data yang dikumpulkan berupa data primer dan data sekunder. Analisis data yang digunakan dalam penelitian ini untuk rumusan masalah yang pertama adalah analisis deskriptif dan 
Stefanus Lugu, *Mitra Musika Lubis, SP. M.Si, Rahma Sari Siregar, SP. M.Si, Analisis Faktor - Faktor Yang Mempengaruhi Pendapatan Nelayan Juragan Tangkapan Ikan Teri (103-114)

untuk rumusan masalah yang kedua adalah analisis regresi linier berganda, uji $t$ dan uji $\mathrm{f}$ dengan alat bantu SPSS 16.0

\section{HASIL DAN PEMBAHASAN}

Berdasarkan hasil observasi penelitian, diketahui bahwa rata-rata biaya produksi nelayan juragan tangkapan ikan teri di Kelurahan Belawan Bahari sebesar Rp.49.497.767, Biaya-biaya itu terdiri dari makanan, lauk dan rokok sebesar Rp.2.879.533, minyak solar sebesar Rp.19.045.000, garam sebesar Rp.12.915.000, gas ukuran 12 kg sebesar Rp.9.715.000, upah tenaga kerja sebesar Rp.4.940.000, dan penyusutan peralatan sebesar Rp.250.000 (Lampiran 4). Sedangkan rata-rata produksi (hasil tangkapan) nelayan juragan yaitu sebesar $1.949 \mathrm{~kg}$ dengan rata-rata jarak tempuh melaut yaitu $31 \mathrm{~km}$.

Dan rata-rata penerimaan nelayan juragan di Kelurahan Belawan Bahari yaitu sebesar Rp.58.474.000 dengan pendapatan bersih yaitu sebesar Rp.8.976.233. Secara lengkap ratarata biaya produksi dan pendapatan nelayan juragan tangkapan ikan teri dapat dilihat pada tabel 12.

Tabel 2. Rata-rata Biaya Produksi dan Pendapatan Nelayan Juragan Tangkapan Ikan Teri.

\begin{tabular}{|c|c|c|c|}
\hline No. & Keterangan & Uraian & Jumlah (Rp/bulan) \\
\hline \multirow[t]{7}{*}{1.} & Biaya produksi & $\begin{array}{l}\text { Makanan dan rokok } \\
\text { (Rp/bulan hari) }\end{array}$ & 2.879 .533 \\
\hline & & Minyak solar (Rp/bulan) & 19.045 .000 \\
\hline & & Garam (Rp/bulan) & 12.915 .000 \\
\hline & & $\begin{array}{l}\text { Gas ukuran } 12 \mathrm{~kg} \\
\text { (Rp/bulan) }\end{array}$ & 9.715 .000 \\
\hline & & Tenaga kerja (Rp/bulan) & 4.940 .000 \\
\hline & & $\begin{array}{l}\text { Penyusutan peralatan } \\
\text { (Rp/bulan) }\end{array}$ & 250.000 \\
\hline & & Total & 49.497 .767 \\
\hline \multirow[t]{2}{*}{2} & Produksi & $\begin{array}{l}\text { Jarak tempuh melaut } \\
(\mathrm{km})\end{array}$ & 31 \\
\hline & & Produksi $(\mathrm{kg} / \mathrm{km})$ & 1.949 \\
\hline \multirow[t]{3}{*}{3} & $\begin{array}{l}\text { Penerimaan dan } \\
\text { pendapatan }\end{array}$ & Penerimaan (Rp/bulan) & 58.474 .000 \\
\hline & & $\begin{array}{l}\text { Biaya produksi } \\
\text { (Rp/bulan) }\end{array}$ & 49.497 .767 \\
\hline & & $\begin{array}{l}\text { Pendapatan bersih } \\
\text { (Rp/bulan) }\end{array}$ & 8.976 .233 \\
\hline
\end{tabular}

Sumber : Data Primer Diolah, 2017. 
Pada tabel 12 dapat dilihat bahwa rata-rata biaya produksi nelayan juragan secara keseluruhan sebesar Rp.49.497.767 untuk memperoleh produksi (hasil tangkapan) ikan teri dengan rata-rata produksi sebesar $1.949 \mathrm{~kg}$. Dan rata-rata pendapatan yang diterima bersih oleh nelayan juragan di Kelurahan Belawan Bahari yaitu sebesar Rp.8.976.233.

Untuk tingkat pendapatan (penerimaan - biaya produksi) per bulan nelayan juragan di Kelurahan Belawan Bahari yang terendah sebesar Rp.2.194.000 dan yang tertinggi sebesar Rp.21.070.000 dengan rata-rata per bulan sebesar Rp.8.976.233.

Untuk biaya produksi per bulan nelayan juragan di Kelurahan Belawan Bahari yang terendah sebesar Rp.40.706.000 dan yang tertinggi sebesar Rp.59.400.000 dengan rata-rata per bulan sebesar Rp.49.497.767.

Untuk tenaga kerja nelayan juragan di Kelurahan Belawan Bahari yang ikut dalam melaut yang terendah adalah 3 orang dan yang tertinggi adalah 5 orang dengan rata-rata tenaga kerja adalah 3,8.

Untuk jarak tempuh melaut nelayan juragan per bulan di Kelurahan Belawan Bahari yang terendah yaitu $20 \mathrm{~km}$ dan yang tertinggi yaitu $40 \mathrm{~km}$ dengan rata-rata jarak tempuh melaut yaitu $30,67 \mathrm{~km}$.

Untuk pengalaman usaha nelayan juragan dalam menangkap ikan teri di Kelurahan Belawan Bahari mempunyai pengalaman minimum 10 tahun dan maximum 15 tahun dengan rata-rata pengalaman usaha yaitu 11,97 tahun. Secara lengkap rata-rata pendapatan dan faktor-faktor yang mempengaruhi pendapatan nelayan juragan dapat dilihat pada tabel 13.

Tabel 13. Rata-rata Pendapatan dan Faktor-faktor Yang Mempengaruhi Pendapatan Nelayan Juragan.

\begin{tabular}{cllll}
\hline No & Keterangan & Minimum & Maximum & Mean \\
\hline 1. & Pendapatan (Rp/bulan) & 2.194 .000 & 21.070 .000 & 8.976 .233 \\
2. & Biaya produksi (Rp/bulan) & 40.706 .000 & 59.400 .000 & 49.497 .767 \\
3. & Tenaga kerja (orang) & 3 & 5 & 3,8 \\
4. & Jarak tempuh melaut (km/bulan) & 20 & 40 & 30,67 \\
5. & Pengalaman usaha (tahun) & 10 & 15 & 11,97 \\
\hline
\end{tabular}


Berdasarkan hasil perhitungan dengan menggunakan alat bantu SPSS 16, hasil yang diperoleh untuk perhitungan regresi linier berganda dari faktor - faktor yang mempengaruhi pendapatan nelayan juragan di Kelurahan Belawan Bahari yaitu biaya produksi, jumlah tenaga kerja, jarak tempuh melaut dan pengalaman usaha terhadap pendapatan nelayan juragan dapat dilihat pada tabel14.

Tabel 14. Analisis Regresi Faktor-faktor Yang Mempengaruhi Pendapatan Nelayan Juragan.

\begin{tabular}{|c|c|c|c|c|c|c|}
\hline & \multirow[t]{2}{*}{ Model } & \multicolumn{2}{|c|}{$\begin{array}{l}\text { Unstandardized } \\
\text { Coefficients }\end{array}$} & \multirow{2}{*}{$\begin{array}{l}\text { Standardized } \\
\text { Coefficients } \\
\text { Beta }\end{array}$} & \multirow{2}{*}{$\mathrm{T}$} & \multirow{2}{*}{ Sig. } \\
\hline & & $\mathrm{B}$ & Std. Error & & & \\
\hline \multirow[t]{5}{*}{1} & (Constant) & $-1,535$ & 4,514 & & $-3,400$ & 0,002 \\
\hline & $\begin{array}{l}\text { Biaya } \\
\text { produksi }\end{array}$ & $-0,073$ & 0,133 & $-0,070$ & $-0,545$ & 0,590 \\
\hline & $\begin{array}{l}\text { Tenaga } \\
\text { kerja } \\
\text { Jarak tempuh }\end{array}$ & 1,709 & 7,632 & 0,275 & 2,239 & 0,034 \\
\hline & melaut & 3,197 & 1,083 & 0,466 & 2,953 & 0,007 \\
\hline & $\begin{array}{l}\text { Pengalaman } \\
\text { usaha }\end{array}$ & 9,711 & 3,938 & 0,401 & 2,466 & 0,021 \\
\hline
\end{tabular}

Sumber : Data Primer Diolah, 2017.

Berdasarkan pada tabel 14 maka dapat diperoleh persamaan analisis regresi linier berganda untuk faktor-faktor yang mempengaruhi pendapatan nelayan juragan di Kelurahan Belawan Bahari Kecamatan Medan Belawan Kota Medan sebagai berikut :

$$
\mathrm{Y}=-1,535+-0,073 \mathrm{X}_{1}+1,709 \mathrm{X}_{2}+3,197 \mathrm{X}_{3}+9,711 \mathrm{X}_{4}+\text { Error }
$$

Keterangan :

$\mathrm{Y}=$ Pendapatan Nelayan Juragan (Rp/bulan) $\mathrm{X}_{1}=$ Biaya Produksi $(\mathrm{Rp} / \mathrm{bulan})$

$\mathrm{X}_{2}=$ Jumlah Tenaga Kerja(jiwa)

$\mathrm{X}_{3}=$ Jarak Tempuh Melaut(Km/bulan) $\mathrm{X}_{4}=$ Pengalaman Usaha(tahun).

Berdasarkan hasil uji F untuk menjelaskan pengaruh variabel independent terhadap variabel dependent dapat dilihat pada tabel 15 . 
Tabel 15. Hasil Uji $\mathrm{F}$ dari Faktor-faktor Yang Mempengaruhi Pendapatan NelayanJuragan

\begin{tabular}{lllllll} 
Model & $\begin{array}{l}\text { Jumlah } \\
\text { Kuadrat }\end{array}$ & Df & $\begin{array}{l}\text { Rata-rata } \\
\text { kuadrat }\end{array}$ & Fhitung & Ftabel & Sig. \\
\hline Regression & 6,828 & 4 & 1,707 & 35,573 & 2,99 & $0,000^{\text {a }}$ \\
Residual & 1,200 & 25 & 4,799 & & \\
Total & 8,028 & 29 & & & \\
\hline Interpretasi & H1ditolak & Signifikan pada tingkat kepercayaan95\% & \\
\hline
\end{tabular}

Sumber : Data Primer Diolah, 2017.

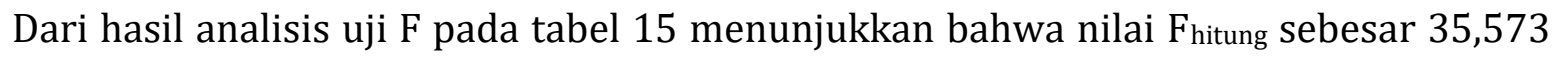
dan nilai signifikansinya sebesar 0,000. Berdasarkan hasil tersebut diketahui bahwa nilai

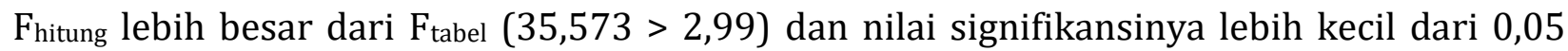
$(0,000<0,05)$, maka H0 ditolak, dan koefisien regresi signifikan secara statistik pada tingkat kepercayaan 95 \%. Hal ini berarti adanya pengaruh biaya produksi, jumlah tenaga kerja, jarak tempuh melaut dan pengalaman usaha secara serempak terhadap pendapatan nelayan juragan di Kelurahan Belawan Bahari Kecamatan Medan Belawan Kota Medan.

Berdasarkan pengujian yang dilakukan secara uji t dapat dijelaskan pengaruh variabel independen secara parsial (satu persatu) terhadap variabel dependen sebagai berikut:

Biaya Produksi $\left(\mathrm{X}_{1}\right)$

Berdasarkan hasil uji t diperoleh t-hitung untuk variabel biaya produksi sebesar 0,545 yang lebih kecil dari t-tabel yaitu 1,708 $(-0,545<1,708)$ dengan nilai signifikansi 0,590 lebih besar dari alpha $\left(0,590>0,05\right.$, maka $\mathrm{H}_{1}$ diterima. Sehingga secara parsial dapat disimpulkan bahwa tingkat biaya produksi tidak berpengaruh nyata terhadap pendapatan nelayan juragan di Kelurahan Belawan Bahari Kecamatan Medan Belawan KotaMedan.

Jumlah Tenaga Kerja(X2)

Berdasarkan hasil uji t diperoleh t-hitung untuk variabel jumlah tenaga kerja sebesar 2,239 yang lebih besar dari t-tabel yaitu 1,708 $(2,239>1,708)$ dengan nilai signifikansi 0,034 lebih kecil dari alpha 0,05 $(0,034<0,05)$, maka $\mathrm{H}_{0}$ ditolak. Sehingga secara parsial 
Stefanus Lugu, *Mitra Musika Lubis, SP. M.Si, Rahma Sari Siregar, SP. M.Si, Analisis Faktor - Faktor Yang Mempengaruhi Pendapatan Nelayan Juragan Tangkapan Ikan Teri (103-114)

dapat disimpulkan bahwa jumlah tenaga kerja berpengaruh nyata terhadap pendapatan nelayan juragan di Kelurahan Belawan Bahari Kecamatan Medan Belawan Kota Medan. Jarak Tempuh Melaut $\left(\mathrm{X}_{3}\right)$

Berdasarkan hasil uji t diperoleh t-hitung untuk variabel jarak tempuh melaut sebesar 2,953 yang lebih besar dari t-tabel yaitu $1,708(2,953>1,708)$ dengan nilai signifikansi 0,007 lebih kecil dari alpha 0,05 $(0,007<0,05)$, maka Ho ditolak. Sehingga secara parsial dapat disimpulkan bahwa jarak tempuh melaut berpengaruh nyata terhadap pendapatan nelayan juragan di Kelurahan Belawan Bahari Kecamatan Medan Belawan Kota Medan.

Pengalaman usaha $\left(\mathrm{X}_{4}\right)$

Berdasarkan hasil uji t diperoleh t-hitung untuk variabel pengalaman usaha sebesar 2,466 yang lebih besar dari t-tabel yaitu 1,708 $(2,466>1,708)$ dengan nilai signifikansi 0,021 lebih kecil dari alpha 0,05 $(0,021<0,05)$, maka $\mathrm{H}_{0}$ ditolak. Sehingga secara parsial dapat disimpulkan bahwa pengalaman usaha berpengaruh nyata terhadap pendapatan nelayan juragan di Kelurahan Belawan Bahari Kecamatan Medan Belawan Kota Medan.

Penelitian ini bertujuan untuk mengetahui gambaran pendapatan nelayan juragan secara deskriptif dan bagaimana pengaruh biaya produksi, jumlah tenaga kerja, jarak tempuh melaut dan pengalaman usaha terhadap pendapatan nelayan juragan. Secara lengkap, analisis faktor-faktor yang mempengaruhi pendapatan nelayan juragan di Kelurahan Belawan Bahari Kecamatan Medan Belawan Kota Medan dapat dibahas sebagai berikut :

Biayaproduksi

Berdasarkan hasil data pada penelitian ini diketahui bahwa biaya produksi nelayan juragan di dominasi oleh modal usaha Rp.45.000.000 - Rp.55.000.000 sebesar 66,67\%. Biaya produksi < Rp.45.000.000 sebesar 16,67\% dan biaya produksi > Rp.55.000.000 sebesar 16,67\%. Biaya produksi adalah biaya-biaya yang dikeluarkan oleh nelayan juragan dalam memperoleh hasilnya. Biaya-biaya itu terdiri dari : makan, rokok, minyak solar, garam, upah tenaga kerja, peralatan menangkap ikan selama sebulan. Biaya produksi secara parsial tidak berpengaruh nyata/signifikan terhadap pendapatan nelayan juragan. Hal ini dapat dilihat dari tingkat signifikansi 0,590 > 0,05. Secara lengkap rata-rata jumlah pendapatan nelayan juragan berdasarkan modal usaha dapat dilihat pada tabel17. 
Tabel 17. Rata-rata Jumlah Pendapatan Nelayan Juragan Berdasarkan Biaya Produksi

\begin{tabular}{clll}
\hline No. & $\begin{array}{l}\text { Biaya produksi } \\
\text { (Rp/bulan) }\end{array}$ & $\begin{array}{l}\text { Jumlah } \\
\text { Sampel }\end{array}$ & $\begin{array}{l}\text { Rata-rata jumlah pendapatan } \\
\text { (Rp/bulan) }\end{array}$ \\
\hline 1. & $<$ Rp.45.000.000 & 5 & 4.215 .000 \\
2. & Rp.45.000.000 & -20 & 7.909 .200 \\
& Rp.55.000.000 & & \\
3. & $>$ Rp.55.000.000 & 5 & 15.665 .000 \\
\hline
\end{tabular}

Sumber : Data Primer Diolah, 2017.

Jumlah TenagaKerja

Berdasarkan hasil data pada penelitian ini, diketahui bahwa jumlah tenaga kerja nelayan juragan di dominasi oleh jumlah tenaga kerja 3 jiwa sebesar 46,67\%, 4 jiwa sebesar $26,67 \%$ dan 5 jiwa sebesar 26,67\%. Tenaga kerja adalah banyaknya orang yang ikut melaut dalam 1 kapal motor yang terdiri dari nahkoda, tukang masak dan anggota yang membantu dalam kapal tersebut. Jumlah tenaga kerja secara parsial berpengaruh nyata terhadap pendapatan nelayan juragan. Hal ini dapat dilihat dari tingkat signifikansi 0,034<0,05. Secara lengkap rata-rata jumlah pendapatan nelayan juragan berdasarkan jumlah tenaga kerja dapat dilihat pada tabel18.

Tabel 18. Rata-rata Jumlah Pendapatan Nelayan Juragan Berdasarkan Jumlah Tenaga Kerja

\begin{tabular}{llll}
\hline No. & $\begin{array}{l}\text { Jumlah Tenaga Kerja } \\
\text { (orang) }\end{array}$ & $\begin{array}{l}\text { Jumlah } \\
\text { Sampel }\end{array}$ & $\begin{array}{l}\text { Rata-rata jumlah pendapatan } \\
\text { (Rp/bulan) }\end{array}$ \\
\hline 1. & 4 & 8 & 4.134 .375 \\
2. & 3 & 14 & 7.479 .071 \\
3. & 5 & 8 & 15.473 .000 \\
\hline
\end{tabular}

Sumber : Data Primer Diolah, 2017.

Jarak Tempuh Melaut

Berdasarkan hasil data pada penelitian ini diketahui bahwa jarak tempuh melaut nelayan juragan di dominasi oleh jarak tempuh melaut 30-32 km sebesar 43,33\%, < $30 \mathrm{~km}$ sebesar 26,67\% dan $>32 \mathrm{~km}$ sebesar 30,00\%. Jarak tempuh melaut adalah rata-rata jarak yang ditempuh oleh nelayan dalam menangkap ikan. Jarak tempuh melaut secara parsial 
Stefanus Lugu, *Mitra Musika Lubis, SP. M.Si, Rahma Sari Siregar, SP. M.Si, Analisis Faktor - Faktor Yang Mempengaruhi Pendapatan Nelayan Juragan Tangkapan Ikan Teri (103-114)

berpengaruh nyata/signifikan terhadap pendapatan nelayan juragan. Hal ini dapat dilihat dari tingkat signifikan $0.007<0,05$. Secara lengkap rata-rata jumlah pendapatan nelayan juragan berdasarkan jarak tempuh melaut dapat dilihat pada tabel 19.

Tabel 19. Rata-rata Jumlah Pendapatan Nelayan Juragan Berdasarkan Jarak Tempuh Melaut

\begin{tabular}{llll}
\hline No & Jarak Tempuh Melaut & Jumlah & Rata-rata pendapatan \\
& (Km/bulan) & Sampel & (Rp/bulan) \\
\hline 1. & $<30$ & 8 & 4.134 .375 \\
2. & $30-32$ & 13 & 7.285 .154 \\
3. & $>32$ & 9 & 15.494 .556 \\
\hline
\end{tabular}

Sumber : Data Primer Diolah, 2017.

Pengalaman Usaha

Berdasarkan hasil data pada penelitian ini diketahui bahwa pengalaman usaha nelayan juragan di dominasi oleh pengalaman usaha 12 tahun sebesar 46,67\%, 10 tahun sebesar 23,33\% dan 15 tahun sebesar 30,00\%. Pengalaman usaha adalah orang yang sudah menjalani profesi hidupnya sebagai nelayan juragan dalam jangka waktu tertentu. Pengalaman usaha secara parsial berpengaruh nyata terhadap pendapatan nelayan juragan. Hal ini dapat dilihat dari tingkat signifikansi 0,021<0,05. Secara lengkap rata-rata jumlah pendapatan nelayan juragan berdasarkan pengalaman usaha dapat dilihat pada tabel 20 .

Tabel 20. Rata-rata Jumlah Pendapatan Nelayan Juragan Berdasarkan Pengalaman Usaha

\begin{tabular}{clll} 
No. & $\begin{array}{l}\text { Pengalaman Usaha } \\
\text { (tahun) }\end{array}$ & $\begin{array}{l}\text { Jumlah } \\
\text { Sampel }\end{array}$ & $\begin{array}{l}\text { Rata-rata jumlah pendapatan } \\
\text { (Rp/bulan) }\end{array}$ \\
\hline 1. & 10 & 7 & 4.229 .111 \\
2. & 12 & 14 & 7.479 .071 \\
3. & 15 & 9 & 15.165 .429 \\
\hline
\end{tabular}

Sumber : Data Primer Diolah, 2017. 


\section{SIMPULAN}

Berdasarkan hasil penelitian, dapat diambil kesimpulan bahwa pendapatan nelayan juragan di Kelurahan Belawan Bahari Kecamatan Medan Belawan sangat bervariasi dari tingkat rendah sampai tingkat yang tertinggi. Dimana pendapatan nelayan juragan tersebut tidak menetap setiap harinya atau setiap bulannya dan rata-rata pendapatan nelayan juragan di Kelurahan Belawan Bahari Kecamatan Medan Belawan Kota Medan adalah Rp. 8.976.233.

Faktor-faktor yang mempengaruhi pendapatan nelayan juragan di Kelurahan Belawan Bahari Kecamatan Medan Belawan Kota Medan yaitu biaya produksi, jumlah tenaga kerja, jarak tempuh melaut dan pengalaman usaha secara serempak memiliki pengaruh nyata terhadap pendapatan nelayan juragan. Secara parsial bahwa jumlah tenaga kerja, jarak tempuh melaut dan pengalaman usaha berpengaruh nyata terhadap pendapatan nelayan juragan dengan nilai t-hitung untuk variabel jumlah tenaga kerja lebih besar dari nilai ttabel yaitu 1,708 $(2,239>1,708)$ dan nilai signifikansi lebih kecil dari alpha 0,05 $(0,034<$ 0,05). Untuk variabel jarak tempuh melaut nilai t-hitung 2,953 lebih besar dari nilai t-tabel yaitu 1,708 $(2,953>1,708)$ dan nilai signifikansi lebih kecil dari alpha $0,05(0,007<0,05)$. Dan untuk variabel pengalaman usaha nilai t-hitung 2,466 lebih besar dari nilai t-tabel yaitu $1,708(2,466>1,708)$ dan nilai signifikansi lebih kecil dari alpha 0,05 $(0,021<0,05)$.

\section{DAFTAR PUSTAKA}

Anggun Rokhmawati, 2016. Karakteristik Nelayan dan Pendapatan Nelayan (Studi Kasus di Desa Jetis Kecamatan Nusawungu Kabupaten Cilacap). Jurnal. Universitas muhammadyah Purwokerto.

Abd. Rahim dan Diah Retno Dwi Hastuti. 2016. Determinan Pendapatan Nelayan Tangkap Tradisional Wilayah Pesisir Barat Kabupaten Barru. Jurnal. Fakultas Ekonomi. Universitas Negeri Makassar.

Badrul Jamal, 2014. Analisis Faktor-Faktor Yang Mempengaruhi Pendapatan Nelayan (studi kasus Nelayan Pesisir Desa Klampis Kecamatan Klampis Kabupaten Bangkalan). Jurnal. Fakultas Ekonomi. UniversitasBrawijaya.

Kamaluddin, Kartika. K, 2014. Kajian Sosial Ekonomi dan Ketahanan Pangan Rumah Tangga Nelayan (Studi Kasus di Desa Galesong Baru Kecamatan Galesong Kabupaten Takalar Provinsi Sulawesi Selatan). Skripsi. Program Studi Agribisnis. Fakultas Pertanian. Universitas Hasanuddin Makassar.

Kusnadi, 2010. Perempuan Pesisir. LkiS. Yogyakarta.

Karof Alfentino Lamia. 2013. Faktor-Faktor Yang Mempengaruhi Tingkat Pendapatan Nelayan (Studi Kasus di Kecamatan Tumpaan Kabupaten Minahasa Selatan). Jurnal. Program Studi Ekonomi Pembangunan. Fakultas Ekonomi dan Bisnis. Universitas Sam Ratulangi.

Menteri Kelautan dan Perikanan No. 18/ Men/ 2002. Tentang Pembangunan Perikanan. RetnodanSantiasih1993.PengembanganDesaPantai,DalamMubyartodkk.DuaPuluh

Tahun Penelitian Pedesaan. Yogyakarta. Aditya Media.

Satria, Arif. 2002. Pengantar Sosiologi Masyarakat Pesisir. Penerbit Pustaka Cisesindo. Jakarta. 
Stefanus Lugu, *Mitra Musika Lubis, SP. M.Si, Rahma Sari Siregar, SP. M.Si, Analisis Faktor - Faktor Yang Mempengaruhi Pendapatan Nelayan Juragan Tangkapan Ikan Teri (103-114)

Sastrawidjaya, 2002. Nelayan Nusantara. Pusat Riset Pengolahan Produk Sosial Ekonomi Kelautan dan Perikanan. Jakarta.

Sasongko Hudoyo, 2006. Pengaruh Perkembangan Pendapatan Nelayan Terhadap Kondisi Fisik Permukiman Nelayan Wilayah Pesisir Kota Pekalongan. Skripsi. Program Studi Perencanaan Wilayah dan Kota. Fakultas Teknik. Universitas Diponegoro. Semarang.

Sukirno, 2006. Makroekonomi, Teori Pengantar. Penerbit PT Raja Grafindo Persada. Jakarta.

Sujarno, 2008. Analisis Faktor-Faktor Yang Mempengaruhi Pendapatan Nelayan (Studi Kasus di Kabupaten Langkat). Tesis. Program Pascasarjana. Universitas Sumatera Utara.

Sugiyanto, 2004. Analisis Statistika Sosial. (Malang : Bayu Media Anggota IKAPI Jatim). Sugiarto, D. Siagian, LS. Sunaryanto, dan DS. Oetomo. 2003. Teknik Sampling. PT Gramedia

Pustaka Utama. Jakarta.

Triana, Dina. 2007. Karakteristik Sosial Ekonomi Masyarakat Nelayan Kapal Motor di Desa Lampulo Kecamatan Kuta Alam Banda Aceh. Skripsi. Unsyiah Darussalam (Tidak Dipublikasikan).

Wahyuningsih, Elizabeth T. Gurning, dan Edhie Wryanto. (1997). Budaya Kerja Nelayan Indonesia di Jawa Tengah (Kasus Masyarakat Nelayan Desa Wonokerto Kulon Kecamatan Wiradesa Kabupaten Pekalongan). Direktorat Jenderal Kebudayaan. Direktorat Sejarah dan Nilai Tradisional. Jakarta.

Yusuf, 2003. Analisis Sebaran Ikan Demersal Yang Tertangkap Dengan Jaring Cantrang di Perairan Kabupaten Demak. Jurnal. Universitas Diponegoro. 